Article

\title{
Facile Synthesis of Vanadium Oxide/Reduced Graphene Oxide Composite Catalysts for Enhanced Hydroxylation of Benzene to Phenol
}

\author{
Yongli Dong ${ }^{1,2}{ }^{,}$Xiaoyu Niu ${ }^{1}$, Weina Song ${ }^{2}$, Dong Wang ${ }^{1}$, Liqiang Chen ${ }^{1}$, Fulong Yuan ${ }^{1, *}$ \\ and Yujun $\mathrm{Zhu}{ }^{1, *}$ \\ 1 Key Laboratory of Functional Inorganic Material Chemistry, Ministry of Education, \\ School of Chemistry and Materials, Heilongjiang University, Harbin 150080, China; dyl709@sina.com (Y.D.); \\ niuxiaoyu2000@126.com (X.N.); wangdongwxr@163.com (D.W.); chlqhhxy@163.com (L.C.) \\ 2 College of Environmental and Chemical Engineering, Heilongjiang University of Science and Technology, \\ Harbin 150022, China; weinasong2013@163.com \\ * Correspondence: fulongyuan2000@yahoo.com (F.Y.); yujunzhu@hlju.edu.cn (Y.Z.); \\ Tel.: +86-451-8660-8610 (F.Y.); +86-451-8660-9650 (Y.Z.)
}

Academic Editor: Frédéric Jaouen

Received: 4 March 2016; Accepted: 10 May 2016; Published: 17 May 2016

\begin{abstract}
The vanadium oxide/reduced graphene oxide $\left(\mathrm{VO}_{x} / \mathrm{RGO}\right)$ composites have been prepared by a simple solvothermal method with the assistance of cationic surfactant cetyltrimethylammonium bromide $(\mathrm{CTAB})$. The microstructure and morphology of the resultant $\mathrm{VO}_{x} / \mathrm{RGO}$ composites have been well characterized. The $\mathrm{VO}_{x}$ nanoparticles are highly dispersed on the RGO sheets with a particle size of about $25 \mathrm{~nm}$. When used as hydroxylation catalysts, the $\mathrm{VO}_{x} / \mathrm{RGO}$ composites are more efficient than individual RGO and vanadium oxide catalysts. The enhanced catalytic performance may be related to not only the well dispersed $\mathrm{VO}_{x}$ active species, but also the hydrophobic surface and huge $\pi$-electron system of RGO for the adsorption and activation of benzene. In addition, the effects of calcination conditions on the microstructure and catalytic properties of $\mathrm{VO}_{x} / \mathrm{RGO}$ composites have also been investigated. The uniform $\mathrm{VO}_{x}$ nanoparticles on the separated RGO sheets show highly efficient catalytic performance, while the formation of aggregated $\mathrm{H}_{x} \mathrm{~V}_{2} \mathrm{O}_{5}$ and bulk $\mathrm{V}_{2} \mathrm{O}_{5}$ species along with the destruction of RGO sheets are poor for the hydroxylation of benzene. Up to $17.4 \%$ yield of phenol is achieved under the optimized catalytic reaction conditions.
\end{abstract}

Keywords: vanadium oxide; reduced graphene oxide; benzene; hydroxylation; phenol

\section{Introduction}

Phenol is an important basic chemical raw material that is widely used as a precursor for phenol resins, fibers, caprolactam, dyestuffs, and medicine. In industry, phenol is in most cases produced by a three-step cumene process, which involves high amounts of pollution, highly energy consumption, and the production of by-production acetone [1,2]. The direct hydroxylation of benzene to phenol has attracted much attention as an alternative method of phenol production. Studies on the direct hydroxylation of benzene using a variety of oxidants, such as nitrous oxide [3,4], hydrogen peroxide [5,6], molecular oxygen [7,8], and a mixture of oxygen and hydrogen [9], have been reported by numerous researchers. Among these oxidants, hydrogen peroxide has a distinct advantage because of the only by-product of water, which would be one of the most useful processes in the future. Besides the traditional catalysis processes, many attempts of direct hydroxylation of benzene have been performed by means of electrochemical oxidation systems [10], photocatalysis systems [11,12], and biocatalysis processes [13]. Furthermore, the production of phenols from renewable resources has been also reported [14,15]. However, the low phenol yield, selectivity, and turnover rate of these 
processes need to be further improved. Thus far, it is still a challenge to fabricate highly selective catalysts with greater phenol yield for the hydroxylation of benzene.

Many kinds of metal species have been investigated in the benzene hydroxylation reaction, such as $\mathrm{Ti}, \mathrm{V}, \mathrm{Fe}, \mathrm{Co}$, and $\mathrm{Cu}[2,6,11,16]$. Among them, vanadium compounds showed excellent catalytic activity in the hydroxylation of benzene, due to their superior redox ability and remarkable stability [16-18]. Various vanadium-based catalysts such as $\mathrm{V} / \mathrm{SiO}_{2}$ [19], vanadium oxide $\left(\mathrm{VO}_{x}\right) /$ clay [20], VS-1 zeolite [21], $\mathrm{V}-\mathrm{N}-\mathrm{C}$ [22], and V-modified mesoporous materials $[5,23,24]$ were investigated for the title reaction. The highly dispersed $\mathrm{VO}_{x}$ nanoparticles (NPs) were found to be highly efficient for the hydroxylation of benzene. As one of the most interesting solid materials, carbon materials (such as activated carbon, MWCNTs, and graphene) can act as catalysts by themselves [25-27] or serve as supports for other active phase [28-32]. Nowadays, the vanadium oxide/carbon composites have attracted increasing attentions. The $\mathrm{V}_{x} \mathrm{O}_{y} @ \mathrm{C}$ [33], $\mathrm{VO}_{2}$-defacts/MWCNTs [34], and V/GO materials [35] have shown good performance in the hydroxylation of benzene to phenol. The high specific surface areas, hydrophobic surface, and carbon defect active sites were found to be facilitative for the adsorption and activation of benzene, as well as the enhancement of catalytic activity of catalysts $[27,31,35]$. However, in spite of the fascinating two-dimensional structure of graphene with huge open $\pi$-electron systems, highly specific surface areas, and hydrophobic surface [27,36,37], to the best of our knowledge, few studies on the fabrication of uniform $\mathrm{VO}_{x}$ nanoparticles (NPs) on graphene for the hydroxylation of benzene to phenol have been reported so far.

In this present work, we report a simple solvothermal strategy for the fabrication of highly dispersed $\mathrm{VO}_{x} \mathrm{NPs}$ loading on graphene with graphite oxide $(\mathrm{GO})$ as the precursor based on its plentiful oxygen functional groups. The direct growth of $\mathrm{VO}_{x}$ on $\mathrm{GO}$ will result in the formation of uneven particles because the negative charges of both metavanadate anions and the GO are not favorable for the assembly of particles. To overcome this difficulty, the positively charged cetyltrimethylammonium bromide (CTAB) was firstly modified onto the surface of GO. Then, the metavanadate anions were well anchored onto the surface of GO due to the intense interactions between the negatively charged metavanadate anions and positively charged CTAB-modified GO. Subsequently, the in-situ growth of uniform $\mathrm{VO}_{x}$ nanoparticles on GO and the simultaneous reduction of $\mathrm{GO}$ to reduced graphene oxide (RGO) were achieved via a solvothermal process in ethanol. Special attentions were paid on the nature, structure, and dispersion of vanadium species, as well as the carbon framework of RGO for the $\mathrm{VO}_{x} / \mathrm{RGO}$ composite catalysts prepared at different conditions. The catalytic performance of resultant $\mathrm{VO}_{x} / \mathrm{RGO}$ composite catalysts was evaluated in the hydroxylation of benzene to phenol with hydrogen peroxide as an oxidant. The effects of catalytic reaction conditions on the catalytic activities have also been discussed.

\section{Results and Discussion}

\subsection{Synthesis and Characterization of $V O_{x} / R G O$ Composites}

The $\mathrm{VO}_{x} / \mathrm{RGO}$ composites are prepared by the solvothermal method in ethanol solution. The synthesis process of $\mathrm{VO}_{x} / \mathrm{RGO}$ composites is shown in Scheme 1. Firstly, the oxygen functional groups of GO served as centers for the anchoring and dispersion of metavanadate anions with the assistance of cationic surfactant CTAB which can bond with both negatively charged GO and metavanadate anions. Subsequently, the in-situ growth of $\mathrm{VO}_{x}$ nanoparticles at the anchoring sites along with the simultaneous reduction of GO to RGO were performed by the solvothermal treatment in ethanol. Finally, a programmed calcination treatment of the as-synthesized $\mathrm{VO}_{x} / \mathrm{RGO}$ composites (VG-as) at different conditions gave rise to the final composite catalysts.

The X-ray diffraction (XRD) patterns of the $\mathrm{GO}$ and various $\mathrm{VO}_{x} / \mathrm{RGO}$ composites are displayed in Figure 1. The GO exhibits an intense characteristic diffraction peak at about $10.2^{\circ}$. After the introduction of vanadium species and the following solvothermal treatment, the characteristic peak of GO disappears in the pattern of VG-as, which can be ascribed to the reduction of various oxygen 
functional groups of GO [38,39]. Meanwhile, a broad weak peak corresponding to the $(002)$ reflection of laminated RGO sheets is observed at around $23.5^{\circ}$ [38]. In addition, no typical peaks of the vanadium oxide can be seen in the pattern of VG-as, which may be due to the high dispersion of $\mathrm{VO}_{x}$ species on the RGO sheets [33]. The VG-A300 and VG-N-A300 exhibit a prominent diffraction peak at around $25.1^{\circ}$, which is corresponding to the (002) reflection of graphite-like stacking of RGO sheets [39]. For comparison, the XRD pattern of RGO with a typical reflection at about $25.1^{\circ}$ was given in Figure $\mathrm{S} 1$. It indicates that the partially reduced GO support of VG-as can be further deoxidized and crystallized upon the calcinations. Furthermore, several weak reflections of $\mathrm{H}_{x} \mathrm{~V}_{2} \mathrm{O}_{5}$ crystallites (PDF 45-0429) present at around $15.4^{\circ}, 20.3^{\circ}, 26.1^{\circ}, 31.1^{\circ}$, and $34.3^{\circ}$ in the patterns of VG-A300 and VG-N-A300, which demonstrates that the vanadium oxide species were successfully introduced onto the RGO support. Moreover, the VG-A300 shows an enhanced peak intensity of $\mathrm{H}_{x} \mathrm{~V}_{2} \mathrm{O}_{5}$ in comparison with that of VG-N-A300, which may be contributed to the aggregation and crystallization of $\mathrm{VO}_{x}$ species on the RGO. Additionally, considering the weak intensity of these peaks, we assume that the introduced $\mathrm{V}$ species may exist not only in the form of $\mathrm{H}_{x} \mathrm{~V}_{2} \mathrm{O}_{5}$ nanocrystal phase but also in the form of amorphous vanadium oxide on the surface of RGO sheets. With increasing calcination temperature in air, the pattern of VG-N-A350 is obviously different from that of VG-N-A300. It is dominated by the diffraction peaks of crystalline $\mathrm{H}_{x} \mathrm{~V}_{2} \mathrm{O}_{5}$ with a very weak $\mathrm{C}(002)$ reflection. The VG-N-A400 displays a pattern similar to that of bulky $\mathrm{V}_{2} \mathrm{O}_{5}$ (PDF 77-2418) with the disappearance of $\mathrm{C}$ (002) reflection, which implies the destruction and possible burning-up of the carbon framework of RGO.

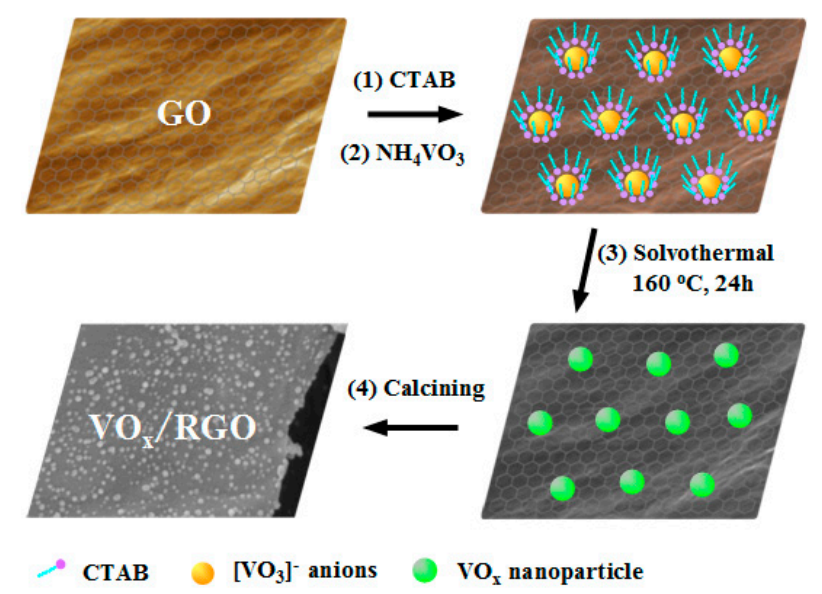

Scheme 1. Schematic illustration of the synthesis process of vanadium oxide/reduced graphene oxide $\left(\mathrm{VO}_{x} / \mathrm{RGO}\right)$ composites.

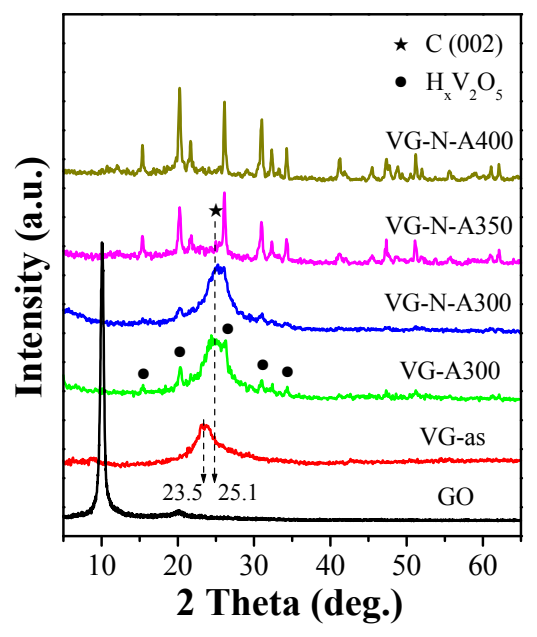

Figure 1. X-ray diffraction (XRD) patterns of the graphene oxide (GO) and various $\mathrm{VO}_{x} / \mathrm{RGO}$ composites. 
The morphology of the $\mathrm{VO}_{x} / \mathrm{RGO}$ composites was gained from the scanning electron microscope (SEM) and transmission electron microscopy (TEM) measurements. The thin and separated graphene sheets with characteristic wrinkled texture and slightly scrolled edges can be seen in the SEM and TEM images of the RGO sample (Figure S2) [38]. From the different magnification SEM images (Figure 2a,b, Figure S3a) and TEM image (Figure S3b) of as-synthesized $\mathrm{VO}_{x} / \mathrm{RGO}$ composites (VG-as), we can see the $\mathrm{VO}_{x}$ nanoparticles (NPs) with uniform size and good dispersion on the RGO sheets. For comparison, a $\mathrm{VO}_{x} / \mathrm{RGO}$ reference sample was also prepared in $\mathrm{H}_{2} \mathrm{O}$ solution with the assistance of CTAB. It is obvious that very large $\mathrm{VO}_{x}$ belts $(>200 \mathrm{~nm}$ ) with poor dispersion on the RGO sheets were obtained as shown in the SEM (Figure 2g) and TEM images (Figure S4a). Additionally, a control experiment for the solvothermal synthesis of $\mathrm{VO}_{x} / \mathrm{RGO}$ composites without the surfactant CTAB was also performed. As illustrated in the SEM (Figure 2h) and TEM (Figure S4b) images of the obtained sample displayed obvious aggregation of $\mathrm{V}$ species along with the uneven distribution of $\mathrm{VO}_{x}$ particles. The above results indicate that the highly dispersed $\mathrm{VO}_{x}$ nanoparticles loading on $\mathrm{RGO}$ sheets can be achieved by the ethanol solvothermal method with the assistance of CTAB. The positively charged $\mathrm{CTAB}$ may play an important role for the introduction and dispersion of $\mathrm{V}$ species owing to its intense interactions with both negatively charged GO and metavanadate anions [40].
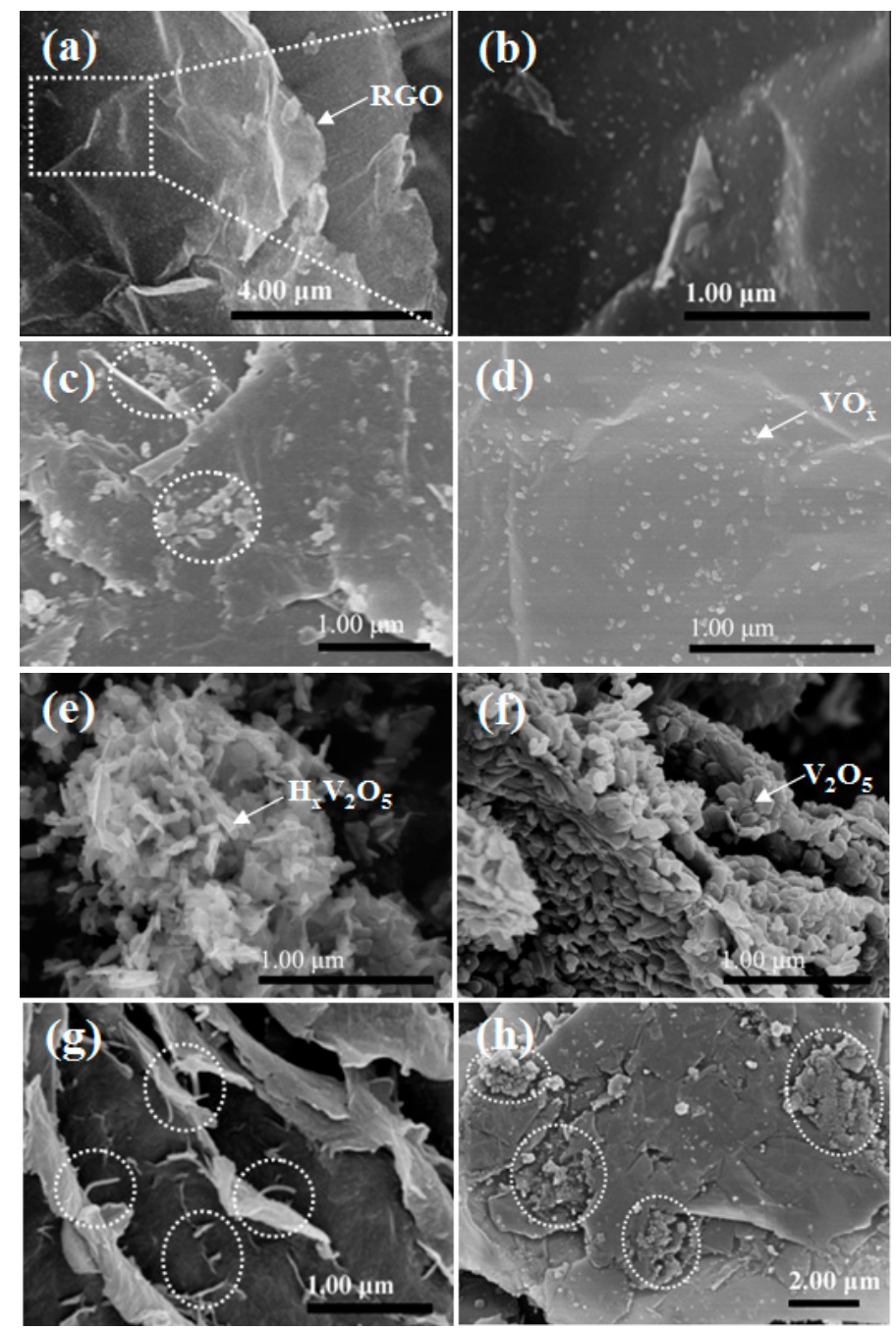

Figure 2. Scanning electron microscope (SEM) images of the VG-as (a and b); VG-A300 (c); VG-N-A300 (d); VG-N-A350 (e); VG-N-A400 (f); $\mathrm{VO}_{x}$ /RGO reference sample obtained in $\mathrm{H}_{2} \mathrm{O}$ solution (g); and $\mathrm{VO}_{x} / \mathrm{RGO}$ reference sample obtained without cetyltrimethylammonium bromide (CTAB) (h). 
Furthermore, it is noted that the calcination conditions showed significant influence on the microstructure of the $\mathrm{VO}_{x} / \mathrm{RGO}$ composites. The highly dispersed $\mathrm{VO}_{x} \mathrm{NPs}$ loading on the RGO sheets can be well seen in the SEM image of VG-N-A300 (Figure 2d). However, a relatively low dispersion of $\mathrm{V}$ species with obvious aggregation on the RGO was observed in the image of VG-A300 (Figure 2c), which may be caused by the suddenly decomposition and even combustion of the residual oxygen functional groups of the RGO during the direct quenching in air. This indicates that the pre-calcining in $\mathrm{N}_{2}$ is necessary for the mild reduction of the residual oxygen functional groups and the maintenance of the high dispersion of $\mathrm{VO}_{x}$ NPs on the RGO support. Moreover, the images of VG-N-A350 (Figure 2e) and VG-N-A400 (Figure 2f) prepared by programmed calcinations in $\mathrm{N}_{2}$ and air atmospheres also exhibited a severe aggregation of $\mathrm{V}$ species along with the decrease of thin RGO sheets due to the increasing calcination temperature in air. Especially, only aggregated vanadium oxide can be easily seen in the image of the VG-N-A400. These results are in good agreement with the analysis of XRD.

Figure 3 shows the TEM and high-resolution TEM (HRTEM) images of the well-structured VG-N-A300 composites. From different magnification TEM images in Figure 3a,b, we can see that the $\mathrm{VO}_{x}$ particles with a uniform size of about $25 \mathrm{~nm}$ are highly dispersed on the RGO sheets. The HRTEM image shows that the distance of two adjacent planes of the selected particle is about $0.34 \mathrm{~nm}$, which is corresponding to the (110) lattice plane of the $\mathrm{H}_{x} \mathrm{~V}_{2} \mathrm{O}_{5}$ crystallites, in accordance with the results of $\mathrm{XRD}$. In addition, the margin of carbon sheets is about 9 layers in thickness, as shown in Figure $3 \mathrm{~d}$, indicating the formation of thin RGO sheets. In a word, the above tests confirm the formation of the $\mathrm{VO}_{x} / \mathrm{RGO}$ composites, in which the $\mathrm{VO}_{x}$ NPs have a uniform size and good dispersion on the RGO support.

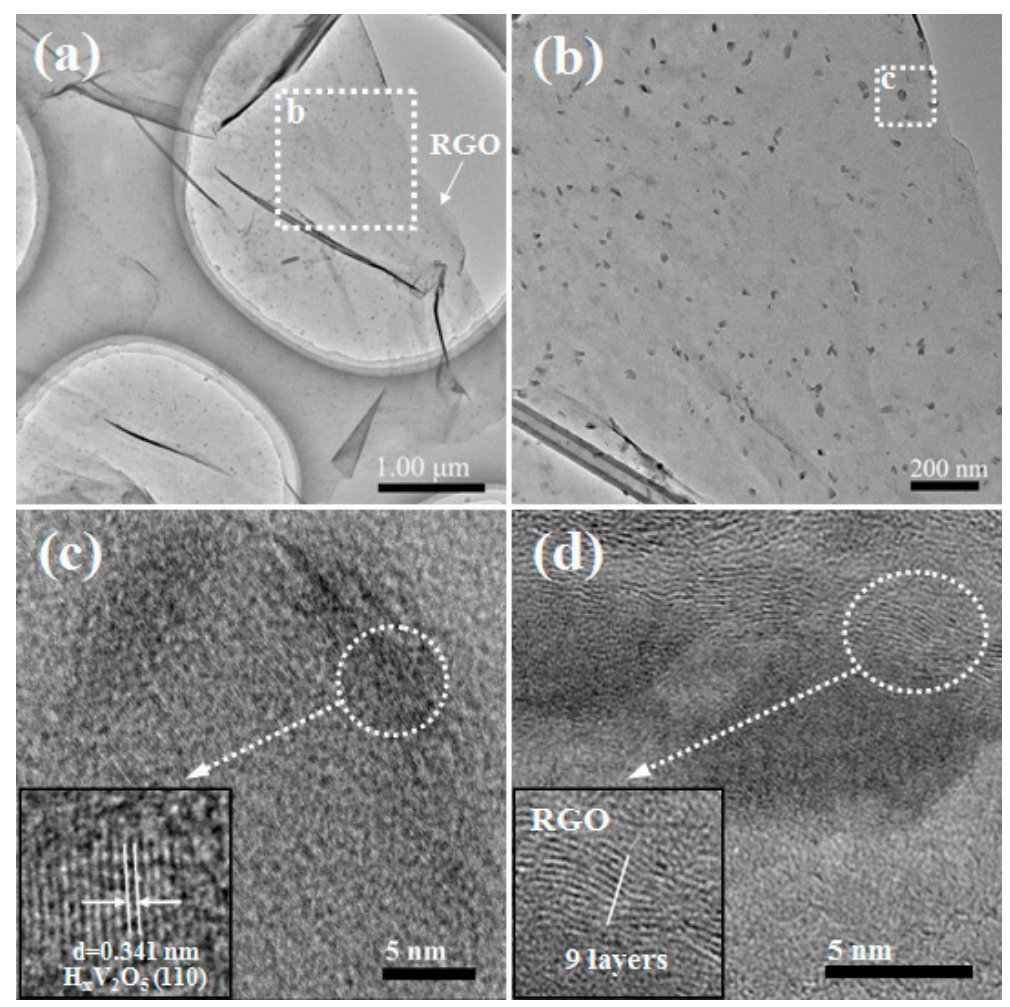

Figure 3. Transmission electron microscopy (TEM) images (a) and (b) and high-resolution TEM (HRTEM) (c) and (d) of the VG-N-A300.

The Fourier translation infrared spectroscopy (FT-IR) spectra of various $\mathrm{VO}_{x} / \mathrm{RGO}$ composites and GO are illustrated in Figure 4a. The spectra of GO shows characteristic absorption peaks of the various oxygen functional groups [38,41]. After the introduction of $\mathrm{V}$ species, the peak intensity of 
these oxygen functional groups obviously decreases in the spectra of the $\mathrm{VO}_{x} / \mathrm{RGO}$ composites due to the deoxygenation reaction upon the solvothermal treatment and the following calcinations [41]. Furthermore, the absorption band at around $1100-1300 \mathrm{~cm}^{-1}$ is strengthening, which may be contributed to the presence of $\mathrm{C}-\mathrm{N}$ stretching vibration originating from the modification of $\mathrm{CTAB}$ for anchoring the $\mathrm{V}$ species onto the GO precursor [42]. Moreover, one additional peak is observed at around $1570 \mathrm{~cm}^{-1}$, corresponding to the formation of the monodentate or bidentate complex between the carboxyl group and vanadium atoms [35,43]. The results imply the strong interactions between the vanadium oxide species and carbon framework. It is noted that the VG-N-A400 gives a different curve from that of the other composites with the disappearance of various oxygen functional groups, which should be attributed to the destruction of the RGO framework, as detected by XRD and SEM. On the other hand, the typical absorption peaks of vanadium oxide species can not be identified in the spectra of VG-as, VG-N-A300, or VG-A300, which may be attributed to their low content of V species on the large amounts of RGO sheets, intense interactions between the two moieties, as well as the relatively low spectral resolution of IR for inorganic compounds. However, the curves of VG-N-A350 and VG-N-A400 display intense absorption peaks at $1023(\mathrm{~V}=\mathrm{O})$ and $832 \mathrm{~cm}^{-1}(\mathrm{~V}-\mathrm{O})$ [43], which can be assigned to the appearance of large amounts of crystalline $\mathrm{H}_{x} \mathrm{~V}_{2} \mathrm{O}_{5}$ and $\mathrm{V}_{2} \mathrm{O}_{5}$ species along with the damage and possible burning-up of the carbon framework of RGO, in good agreement with the results of XRD and SEM analysis (Figure 2e,f).
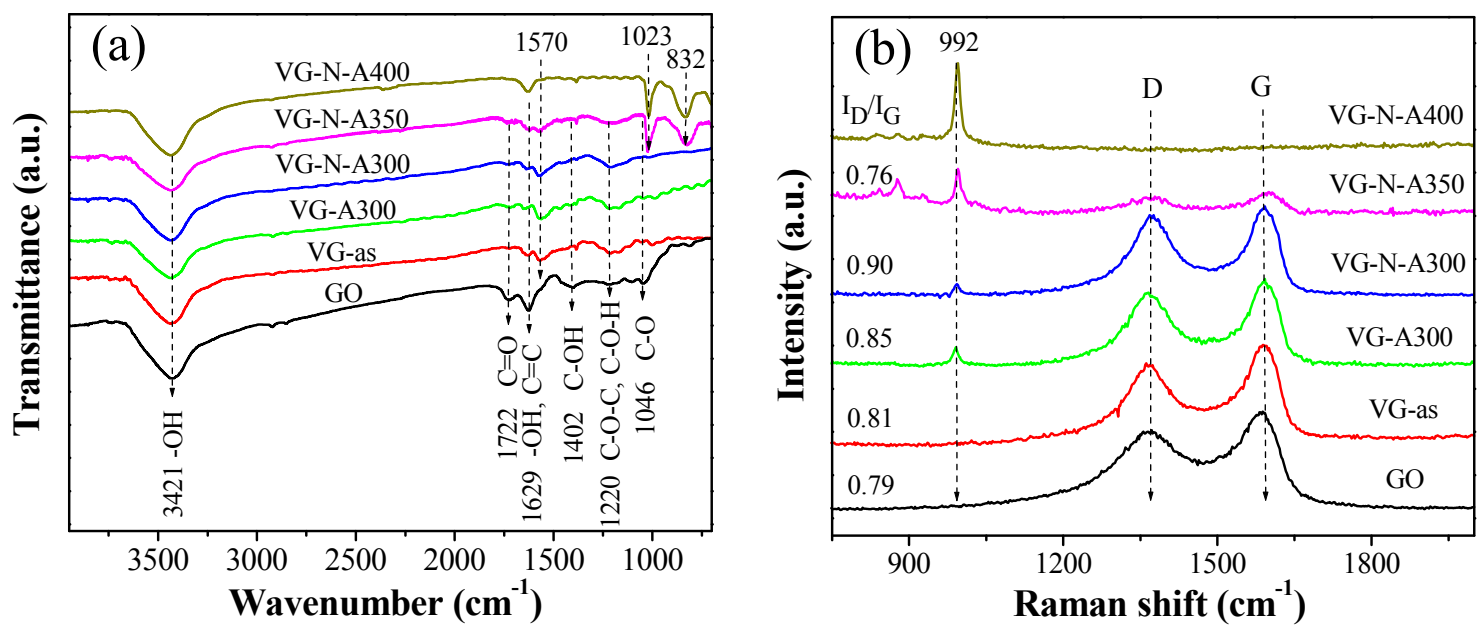

Figure 4. Fourier translation infrared spectroscopy (FT-IR) spectra (a) and Raman spectra (b) of GO and various $\mathrm{VO}_{x} / \mathrm{RGO}$ composites.

The Raman spectra of various $\mathrm{VO}_{x} / \mathrm{RGO}$ composites and GO are demonstrated in Figure $4 \mathrm{~b}$. The spectra of GO, VG-as, VG-A300, VG-N-A300, and VG-N-A350 all display a characteristic G band at about $1586 \mathrm{~cm}^{-1}$ with a D band at around $1365 \mathrm{~cm}^{-1}$, corresponding to the ordered $s p^{2}$-bonded carbon atoms and the disordered modes, respectively [35,41]. The intensity ratio of $\mathrm{D}$ to $\mathrm{G}$ band $\left(\mathrm{I}_{\mathrm{D}} / \mathrm{I}_{\mathrm{G}}\right)$ often affords information about the carbon structure $[44,45]$. The $\mathrm{I}_{\mathrm{D}} / \mathrm{I}_{\mathrm{G}}$ ratio increases clearly from 0.79 (GO) up to $0.81,0.85$ and 0.90 for the VG-as, VG-A300, and VG-N-A300, respectively. The highest $\mathrm{I}_{\mathrm{D}} / \mathrm{I}_{\mathrm{G}}$ ratio of VG-N-A300 should be ascribed to not only the decrease of the average size of $s p^{2}$ carbon domains upon the deoxidization, but also the disordered structure induced by intensive interactions between the highly dispersed $\mathrm{VO}_{x}$ species and RGO [38]. Notably, both the D and $\mathrm{G}$ bands decrease sharply in the curve of VG-N-A350 and disappear in the curve of VG-N-A400. This can be ascribed to the destruction of the RGO sheets in the $\mathrm{VO}_{x} / \mathrm{RGO}$ composites. In addition, the spectrum of VG-as shows no typical peaks of vanadium oxide, which may be due to the high dispersion of amorphous $\mathrm{VO}_{x}$ species on the RGO. After the calcinations, the VG-N-A300 shows a very weak Raman peak at around $992 \mathrm{~cm}^{-1}$, corresponding to the appearance of crystalline vanadium oxide species. Moreover, the peak intensity increases gradually for the VG-A300, VG-N-A350, and 
VG-N-A400, which may be attributed to the increasing aggregation and crystallization of the vanadium oxide species as discussed above in XRD, FT-IR, and morphological analysis.

The surface composition of the VG-N-A300 composite catalyst was analyzed by X-ray photoelectron spectroscopy (XPS). As shown in Figure 5a, the peaks belonging to $\mathrm{C}, \mathrm{O}, \mathrm{V}$, and $\mathrm{N}$ can be clearly seen in the wide scan spectrum of VG-N-A300. The relative atomic concentrations of $\mathrm{C}, \mathrm{O}, \mathrm{V}$, and $\mathrm{N}$ are $79.3 \%, 16.0 \%, 3.2 \%$, and $1.5 \%$ (Table S1), respectively. The C1s spectrum of the sample can be deconvoluted into five peaks corresponding to different carbon species (Figure $5 b$ ). The graphitic sp2 carbon $(\mathrm{C}-\mathrm{C})$ dominates the spectrum with a binding energy of $284.6 \mathrm{eV}$. Four other small peaks at higher binding energy indicate the existence of $\mathrm{C}-\mathrm{N}(285.6 \mathrm{eV}), \mathrm{C}-\mathrm{O}(286.5 \mathrm{eV}), \mathrm{C}=\mathrm{O}(287.4 \mathrm{eV})$, and $\mathrm{O}=\mathrm{C}-\mathrm{OH}$ bonds $(288.6 \mathrm{eV})[41,44]$. It is noticed that the various oxygen-containing groups have much lower peaks than that in the original GO (Figure S5). The peak area ratios of carbon-containing bonds to total area are also calculated and listed in Table S1. The result further affirms the removal of oxygen functional groups in $\mathrm{GO}$ to form $\mathrm{RGO}$ in the preparation of $\mathrm{VO}_{x} / \mathrm{RGO}$ composites [40]. In addition, the presence of $\mathrm{C}-\mathrm{N}$ species should be arising from the using of CTAB in the preparation process $[40,45]$. As illustrated in the morphological analysis (Figure S4), obvious aggregation of vanadium oxide with poor dispersion was observed for the reference $\mathrm{VO}_{x} / \mathrm{RGO}$ sample without the use of CTAB. Herein, we assume that the presence of $\mathrm{C}-\mathrm{N}$ species would be beneficial for the anchoring and dispersion of $\mathrm{VO}_{x}$ NPs on the surface of RGO. The V2 $p_{3 / 2}$ spectrum of the VG-N-A300 in Figure $5 \mathrm{c}$ can be deconvoluted into two peaks at the binding energy of 517.3 and $516.3 \mathrm{eV}$, corresponding to the $\mathrm{V}^{5+}$ and $\mathrm{V}^{4+}$ states in the vanadium oxides, respectively [43,46]. As described in Table S1, the V species exist mainly as $\mathrm{V}^{5+}$ state $(84.4 \%)$ on the RGO support along with the presence of relatively small amount of $\mathrm{V}^{4+}$ species (15.6\%). The presence of $\mathrm{V}^{4+}$ species can be mainly ascribed to the reduction of $\mathrm{V}^{5+}$ species by carbon species or $\mathrm{NH}_{3}$ produced via decomposition of the precursor used. In the O1s spectrum (Figure $5 \mathrm{~d}$ ), the dominant peak at $530.1 \mathrm{eV}$ belongs to lattice oxygen from the $\mathrm{V}-\mathrm{O}$ species [43]. In addition, two weak peaks at $531.5 \mathrm{eV}(\mathrm{C}=\mathrm{O})$ and $533.4 \mathrm{eV}(\mathrm{O}-\mathrm{H}$ and $\mathrm{C}-\mathrm{O})$ can also be clearly observed [40]. This is consistent with the results of the $\mathrm{C} 1 \mathrm{~s}$ and $\mathrm{V} 2 \mathrm{p}_{3 / 2}$ spectra. The above analysis of XPS further proves the fabrication of $\mathrm{VO}_{x} / \mathrm{RGO}$ composites, in which the highly dispersed $\mathrm{VO}_{x}$ species exist mainly as mixed $\mathrm{V}^{5+}$ and $\mathrm{V}^{4+}$ states on the RGO support.
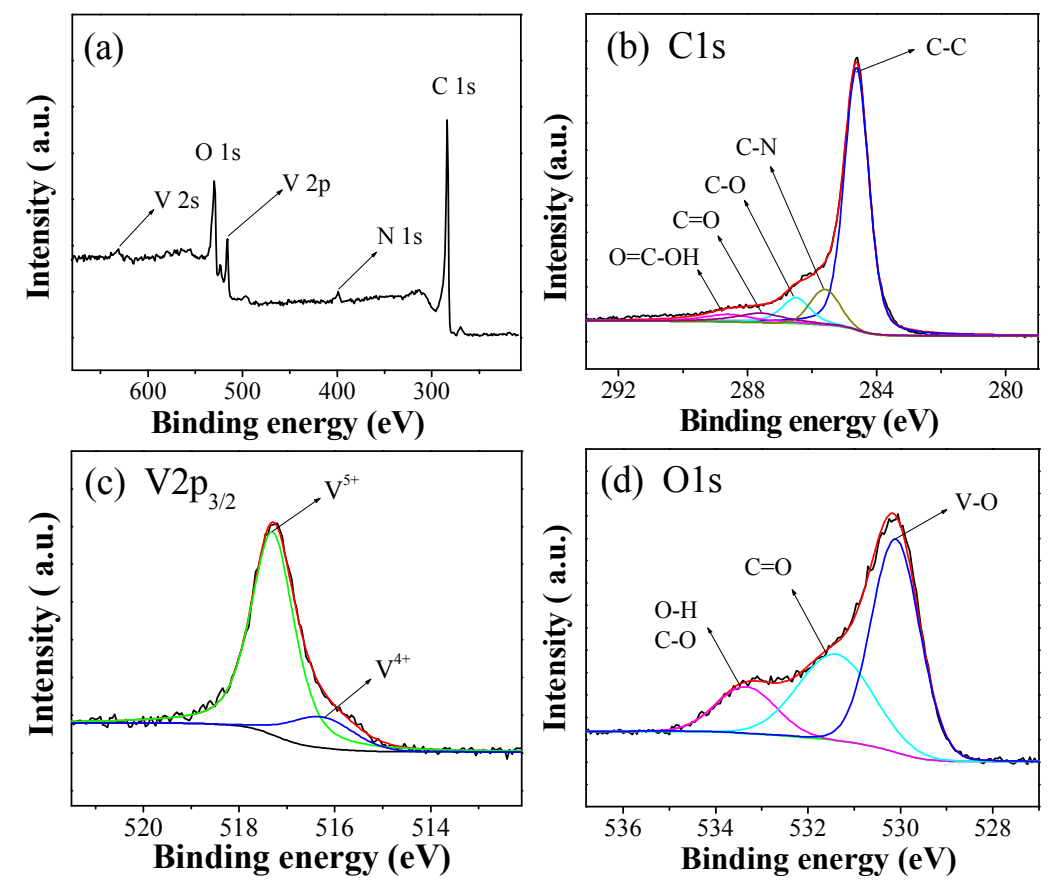

Figure 5. X-ray photoelectron spectroscopy (XPS) survey spectra (a); C1s (b); V2 $\mathrm{p}_{3 / 2}$ (c) and O1s (d) of the VG-N-A300 composites. 
Further insight into the structure and distribution of $\mathrm{V}$ species for various $\mathrm{VO}_{x} / \mathrm{RGO}$ composites was investigated by the measurements of ultraviolet-visible diffuse reflectance spectrum (UV-Vis DRS) and temperature-programmed reduction of hydrogen $\left(\mathrm{H}_{2}-\mathrm{TPR}\right)$. The UV-Vis DRS curves of the $\mathrm{VO}_{x} / \mathrm{RGO}$ composites obtained at different calcination conditions are illustrated in Figure 6a. It is clear that an intense absorption band appears at about $259 \mathrm{~nm}$ in the spectrum of VG-as, which can be attributed to the charge-transfer transitions of $\mathrm{O}^{2-}$ to metal center $\mathrm{V}$ for the highly dispersed amorphous V species [23]. Followed by the calcinations, the absorption band is blue-shifted to $241 \mathrm{~nm}$ for the spectrum of VG-N-A300. Furthermore, one additional shoulder peak is also observed at $273 \mathrm{~nm}$, which could be assigned to charge-transfer transitions of $\mathrm{O}^{2-}$ to $\mathrm{V}$ for the $\mathrm{H}_{x} \mathrm{~V}_{2} \mathrm{O}_{5}$ crystallite species. The spectrum of VG-A300 shows enhanced absorption bands at about 273 and $405 \mathrm{~nm}$ in comparison with that of VG-N-A300, which should be contributed to the increase and aggregation of $\mathrm{H}_{x} \mathrm{~V}_{2} \mathrm{O}_{5}$ species. With increasing calcination temperature in air, the absorption spectrum of VG-N-A350 changes significantly. The maximum absorption band shows an obvious red shift to $405 \mathrm{~nm}$, which can be associated with the presence of $\mathrm{H}_{x} \mathrm{~V}_{2} \mathrm{O}_{5}$ crystallites. Moreover, the absorption band of VG-N-A400 further shifts to higher wavelength and the maximum absorption signal begin from about $485 \mathrm{~nm}$, which can be assigned to the formation of bulk $\mathrm{V}_{2} \mathrm{O}_{5}$ species $[23,47]$.
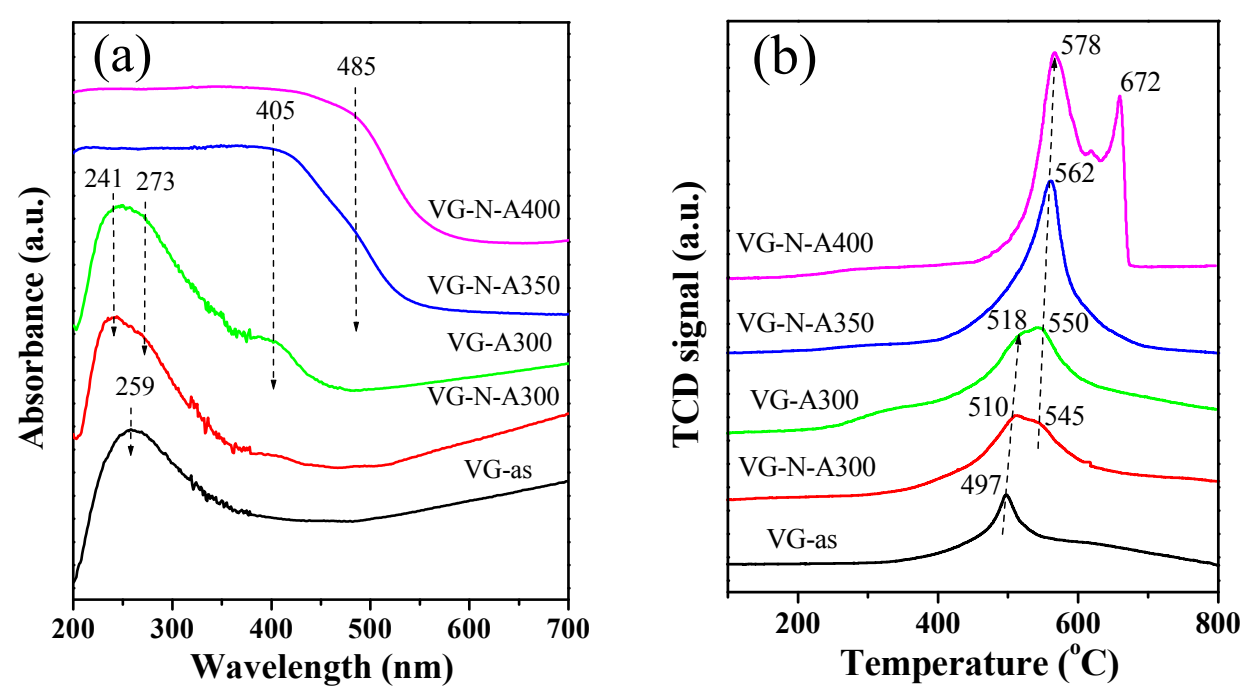

Figure 6. Ultraviolet-visible diffuse reflectance spectrum (UV-Vis DRS) curves (a) and temperatureprogrammed reduction of hydrogen $\left(\mathrm{H}_{2}\right.$-TPR) profiles $(\mathbf{b})$ of various $\mathrm{VO}_{x} / \mathrm{RGO}$ composites.

Figure $6 \mathrm{~b}$ demonstrates the $\mathrm{H}_{2}$-TPR profiles of various $\mathrm{VO}_{x} / \mathrm{RGO}$ composites. The profile of VG-as exhibits a prominent reduction peak at about $497^{\circ} \mathrm{C}$. This can be contributed to the amorphous $\mathrm{VO}_{x}$ species highly dispersed on the RGO support $[23,24]$. After the calcinations, the curve of VG-N-A300 shows an intense reduction peak at $510{ }^{\circ} \mathrm{C}$ with a shoulder at $545^{\circ} \mathrm{C}$, which can be assigned to the reduction of amorphous $\mathrm{VO}_{x}$ and crystalline $\mathrm{H}_{x} \mathrm{~V}_{2} \mathrm{O}_{5}$ species, respectively. It is noted that the two reduction peaks shift further to higher temperatures and appear at 518 and $550{ }^{\circ} \mathrm{C}$ in the curve of VG-A300, which should be devoted to the aggregation of $\mathrm{VO}_{x}$ species and their enlarged particle size, as illustrated by SEM image (Figure 2c). Additionally, the VG-A300 exhibits a larger reduction peak of $\mathrm{H}_{x} \mathrm{~V}_{2} \mathrm{O}_{5}$ species than that of VG-N-A300, suggesting an increase of $\mathrm{H}_{x} \mathrm{~V}_{2} \mathrm{O}_{5}$ species on the RGO support upon the direct calcination in air. In the curve of VG-N-A350, only one prominent reduction peak assigned to the $\mathrm{H}_{x} \mathrm{~V}_{2} \mathrm{O}_{5}$ crystallites can be observed at around $562{ }^{\circ} \mathrm{C}$, which implies significant crystallization of disordered $\mathrm{VO}_{x}$ to $\mathrm{H}_{x} \mathrm{~V}_{2} \mathrm{O}_{5}$ crystallites, in accordance with the results of XRD. Moreover, the VG-N-A400 displays a similar curve to that of the bulky $\mathrm{V}_{2} \mathrm{O}_{5}$ (Figure S6) with two intense reduction peaks at about 578 and $672{ }^{\circ} \mathrm{C}$, which suggests further transition of vanadium species from $\mathrm{H}_{x} \mathrm{~V}_{2} \mathrm{O}_{5}$ crystallites to bulky $\mathrm{V}_{2} \mathrm{O}_{5}$ with an increasing calcination temperature. 
Additionally, the static water contact angle measurements were performed to investigate the surface properties of various $\mathrm{VO}_{x} / \mathrm{RGO}$ composite catalysts. The contact angle pictures of the $\mathrm{VO}_{x} / \mathrm{RGO}$ catalysts, RGO support, and graphite reference sample were demonstrated in Figure S7. It is noted that a large contact angle of RGO $\left(85.1^{\circ}\right)$ was obtained, which is similar to that of graphite $\left(86.2^{\circ}\right)$, suggesting a hydrophobic surface. Meanwhile, the VG-N-A300 exhibits a contact angle of $77.0^{\circ}$, which indicates that the hydrophobic structure of RGO support was well maintained. However, the VG-N-A350 and VG-N-A400 show obviously decreased contact angles of $60.5^{\circ}$ and $38.0^{\circ}$, respectively. It implies the gradually destruction of hydrophobic RGO framework and the increase of hydrophilic vanadium oxide crystal species with the increasing calcination temperature, in good agreement with the results of XRD, SEM, IR, Raman, $\mathrm{H}_{2}$-TPR, and UV-Vis DRS.

In summary, the above results from XRD, SEM, TEM, FT-IR, Raman, XPS, XRF, TPR, UV-Vis DRS, and contact angle analysis clearly show that the highly dispersed $\mathrm{VO}_{x} \mathrm{NPs}$ loading on the reduced graphene oxide $\left(\mathrm{VO}_{x} / \mathrm{RGO}\right)$ were successfully prepared by a simple solvothermal method, in which the intensive interactions may exist between the $\mathrm{VO}_{x}$ species and RGO sheets. It was also found that the calcination conditions show noticeable effects on the $\mathrm{C}$ framework and $\mathrm{V}$ species of the $\mathrm{VO}_{x} / \mathrm{RGO}$ composites. An initial thermal treatment in $\mathrm{N}_{2}$ is necessary to maintain the high dispersion of $\mathrm{VO}_{x}$ species on the RGO support. Herein, the well-structured $\mathrm{VO}_{x} / \mathrm{RGO}$ composite catalyst (VG-N-A300) has been achieved by the programmed calcinations in $\mathrm{N}_{2}$ and air atmospheres, and the highly dispersed $\mathrm{VO}_{x} \mathrm{NPs}$ exist mainly as amorphous $\mathrm{VO}_{x}$ and $\mathrm{H}_{x} \mathrm{~V}_{2} \mathrm{O}_{5}$ nanocrystal species with the presence of mixed $\mathrm{V}^{5+}$ and $\mathrm{V}^{4+}$ states. At the same time, a much higher calcination temperature in air $\left(\geqslant 350{ }^{\circ} \mathrm{C}\right)$ would also lead to the aggregation and change of $\mathrm{V}$ species as well as the destruction of the RGO framework.

\subsection{Hydroxylation of Benzene}

The catalytic performance of $\mathrm{VO}_{x} / \mathrm{RGO}$ composites was tested in the liquid-phase hydroxylation of benzene to phenol using hydrogen peroxide as the oxidant. The catalytic activities of various $\mathrm{VO}_{x} /$ RGO composites, $\mathrm{V}_{2} \mathrm{O}_{5}$, and RGO reference samples are summarized in Table 1 . The RGO sample exhibits a benzene conversion of $0.5 \%$ and phenol yield of $0.4 \%$ with a selectivity of $75.8 \%$, attributing to the intrinsic activity of $\pi$-system of graphene in activation of $\mathrm{H}_{2} \mathrm{O}_{2}$ and the $\pi-\pi$ interaction between graphene and benzene ring [27]. The $\mathrm{V}_{2} \mathrm{O}_{5}$ catalyst gives a benzene conversion of $12.9 \%$ and phenol yield of $9.2 \%$ with a phenol selectivity of $71.5 \%$. It is noted that the VG-as displays an obviously higher phenol yield (11.2\%) and selectivity (93.0\%) than those of the individual RGO and $\mathrm{V}_{2} \mathrm{O}_{5}$ catalysts. After the calcinations, among the various $\mathrm{VO}_{x} / \mathrm{RGO}$ catalysts, the VG-N-A300 shows the highest benzene conversion $(15.7 \%)$ and phenol yield $(14.6 \%)$ with a phenol selectivity of $92.7 \%$. The hydroquinone (HQ) and benzoquinone (BQ) are main byproducts for the present research. The enhanced catalytic performance of VG-N-A300 may be attributed to the uniformly dispersed $\mathrm{VO}_{x}$ active species, the hydrophobic RGO surface for good benzene adsorption ability, as well as the huge $\pi$-electron system of RGO for the activation of benzene $[27,31,35]$. On the other hand, the lower catalytic activity of VG-A300 than that of VG-N-A300 can be assigned to the aggregation of V species on the RGO support arising from the lack of initial calcination in $\mathrm{N}_{2}$. However, even if the VG-N-A350 and VG-N-A400 were obtained by programmed calcination in $\mathrm{N}_{2}$ and air atmospheres, the higher calcination temperature in air would also lead to the severe aggregation $\mathrm{V}$ species along with the increase of particle size and the destruction of the RGO framework. As a result, the catalytic activities of VG-N-A350 and VG-N-A400 catalysts gradually decrease. In particular, the VG-N-A400 shows the lowest phenol yield (10.7\%) and phenol selectivity $(78.5 \%)$, which can be attributed to the formation of bulk $\mathrm{V}_{2} \mathrm{O}_{5}$ crystal and the destruction of the RGO support. In addition, the turnover number (TON) of the various catalysts was also calculated on the basis of $\mathrm{V}$ atoms present in the whole catalyst sample. The TON of 39.9, 35.2, 46.3, 12.6, and 9.0 were obtained for the VG-as, VG-A300, VG-N-A300, VG-N-A350, and VG-N-A400 catalysts (Table 1), respectively. In combination with the results of the TON and catalyst characterization, it implies that a smaller particle size and higher dispersion of the $\mathrm{VO}_{x}$ species loading on the RGO sheets would expose more vanadium active sites 
for the hydroxylation of benzene to phenol; thus, the largest TON was achieved over the VG-N-A300 catalyst. Moreover, the leaching of vanadium species from the VG-N-A300 composite catalyst was also tested. It indicated that about $30 \%$ of V species was leached from the VG-N-A300 catalyst after a normal catalytic run. The dissolved $\mathrm{V}$ species in a liquid reaction system would show some effects on the catalytic performance to some extent due to their catalytic decomposition and/or activation of $\mathrm{H}_{2} \mathrm{O}_{2}$. Thus, the hot filtration experiment was performed over the VG-N-A300 catalyst. After a normal catalytic run for $4 \mathrm{~h}$, the solid catalyst was firstly filtrated from the reaction system; then, another $0.3 \mathrm{~mL}$ of benzene and $1.5 \mathrm{~mL}$ of $\mathrm{H}_{2} \mathrm{O}_{2}$ were added to the liquid system, and the reaction was carried out for another $4 \mathrm{~h}$. The results of catalytic testing showed that no more phenol had been produced than the only normal catalytic run. It implies that the leached V species show negligible catalytic performance in benzene hydroxylation.

Table 1. The hydroxylation of benzene to phenol over various catalysts ${ }^{a}$.

\begin{tabular}{|c|c|c|c|c|c|c|c|}
\hline Sample & $V^{b}(w t \%)$ & $\begin{array}{c}\text { Benzene } \\
\text { Conversion }(\%)\end{array}$ & $\begin{array}{l}\text { Selectivity to } \\
\text { Phenol (\%) }\end{array}$ & $\begin{array}{l}\text { Selectivity } \\
\text { to } \mathrm{BQ}(\%)\end{array}$ & $\begin{array}{l}\text { Selectivity } \\
\text { to HQ (\%) }\end{array}$ & $\begin{array}{c}\text { Yield of } \\
\text { Phenol (\%) }\end{array}$ & TON $^{c}$ \\
\hline RGO & - & 0.5 & 75.8 & 24.2 & - & 0.4 & - \\
\hline $\mathrm{V}_{2} \mathrm{O}_{5}$ & - & 12.9 & 71.5 & 3.6 & 24.9 & 9.2 & - \\
\hline VG-as & 9.6 & 12.0 & 93.0 & - & 7.0 & 11.2 & 39.9 \\
\hline VG-A300 & 12.0 & 13.7 & 89.6 & 1.7 & 8.7 & 12.3 & 35.2 \\
\hline VG-N-A300 & 10.8 & 15.7 & 92.7 & - & 7.3 & 14.6 & 46.3 \\
\hline VG-N-A350 & 32.2 & 13.7 & 86.8 & 2.3 & 10.9 & 11.9 & 12.6 \\
\hline VG-N-A400 & 40.8 & 13.6 & 78.5 & 3.4 & 18.1 & 10.7 & 9.0 \\
\hline
\end{tabular}

Therefore, it can be concluded that the $\mathrm{VO}_{x} / \mathrm{RGO}$ composites are more efficient than the individual RGO and vanadium oxide catalyst. The calcination conditions show significant influence on the catalytic properties of $\mathrm{VO}_{x} / \mathrm{RGO}$ composites owing to the change of the microstructure of $\mathrm{V}$ species and the RGO support. The uniform $\mathrm{VO}_{x} \mathrm{NPs}$ with high dispersion on the separated RGO sheets show a highly efficient catalytic performance, while the formation of a large amount of aggregated $\mathrm{H}_{x} \mathrm{~V}_{2} \mathrm{O}_{5}$ and bulk $\mathrm{V}_{2} \mathrm{O}_{5}$ species along with the destruction of RGO sheets are poor for the hydroxylation of benzene.

In addition, the effects of various reaction conditions including reaction temperature, reaction time, and catalyst amount on the hydroxylation of benzene were also investigated over the VG-N-A300 catalyst. As illustrated in Figure 7a, a relatively low benzene conversion of $8.5 \%$ and phenol yield of $6.5 \%$ with a phenol selectivity of $76.5 \%$ are obtained at a reaction temperature of $30{ }^{\circ} \mathrm{C}$. With the rising of reaction temperature from 30 to $50^{\circ} \mathrm{C}$, the benzene conversion and phenol yield increases quickly to $16.4 \%$ and $15.2 \%$, respectively. This indicates that the rising temperature is beneficial to the hydroxylation reaction because the $\mathrm{H}_{2} \mathrm{O}_{2}$ may be decomposed to produce more active species with the increasing temperature [16]. However, when the temperature is increased up to $65^{\circ} \mathrm{C}$, the phenol yield gradually drops to $12.6 \%$, owing to the more drastic self-decomposition of $\mathrm{H}_{2} \mathrm{O}_{2}$ and the further oxidation of products at higher temperature $[19,23]$. Furthermore, the curve of phenol selectivity showed trends similar to the phenol yield, and a better phenol selectivity of $92.8 \%$ was obtained at $50{ }^{\circ} \mathrm{C}$. The above results indicate that a broad low-temperature range of $40-60^{\circ} \mathrm{C}$ is more suitable for the present hydroxylation reaction over the $\mathrm{VO}_{x} / \mathrm{RGO}$ composite catalysts.

The influence of the reaction time on the hydroxylation of benzene was studied by several separate reactions at the reaction temperature of $50{ }^{\circ} \mathrm{C}$, as shown in Figure $7 \mathrm{~b}$. It can be seen that the benzene conversion and phenol yield increase from $9.8 \%$ and $7.7 \%$ gradually up to $17.4 \%$ and $16.2 \%$, respectively, when the reaction time is prolonged from $1 \mathrm{~h}$ to $5 \mathrm{~h}$. At the same time, the highest phenol selectivity of $93.1 \%$ is achieved. However, with a further increase in reaction time, the benzene conversion, phenol yield, and phenol selectivity all show slight decreases, which could be attributed to the further oxidation of phenol as well as byproducts of hydroquinone and benzoquinone to other byproducts, 
such as tar that can not detected by gas chromatography with a FID detector. The effect of the amount of VG-N-A300 catalyst on the catalytic activities is demonstrated in Figure 7c. With the increasing catalyst amount, the highest benzene conversion (18.7\%) and phenol yield (17.4\%) were achieved when a 7.5-mg catalyst is used. As the catalyst amount is further increased to $12.5 \mathrm{mg}$, the phenol yield obviously decreases to $16.0 \%$. Furthermore, following the increase of catalyst amount from 2.5 to $12.5 \mathrm{mg}$, the phenol selectivity decreases gradually from 93.5 to $85.2 \%$. In general, the more the amount of catalyst is used, the more vanadium sites may be provided, which is in favor of not only the hydroxylation of benzene to phenol, but also the acceleration of self-decomposition of hydrogen peroxide to oxygen and water $[16,20,23]$. Thus, the decreased results of catalytic properties could be attributed to the consumption of more hydrogen peroxide over excessive amounts of catalyst.
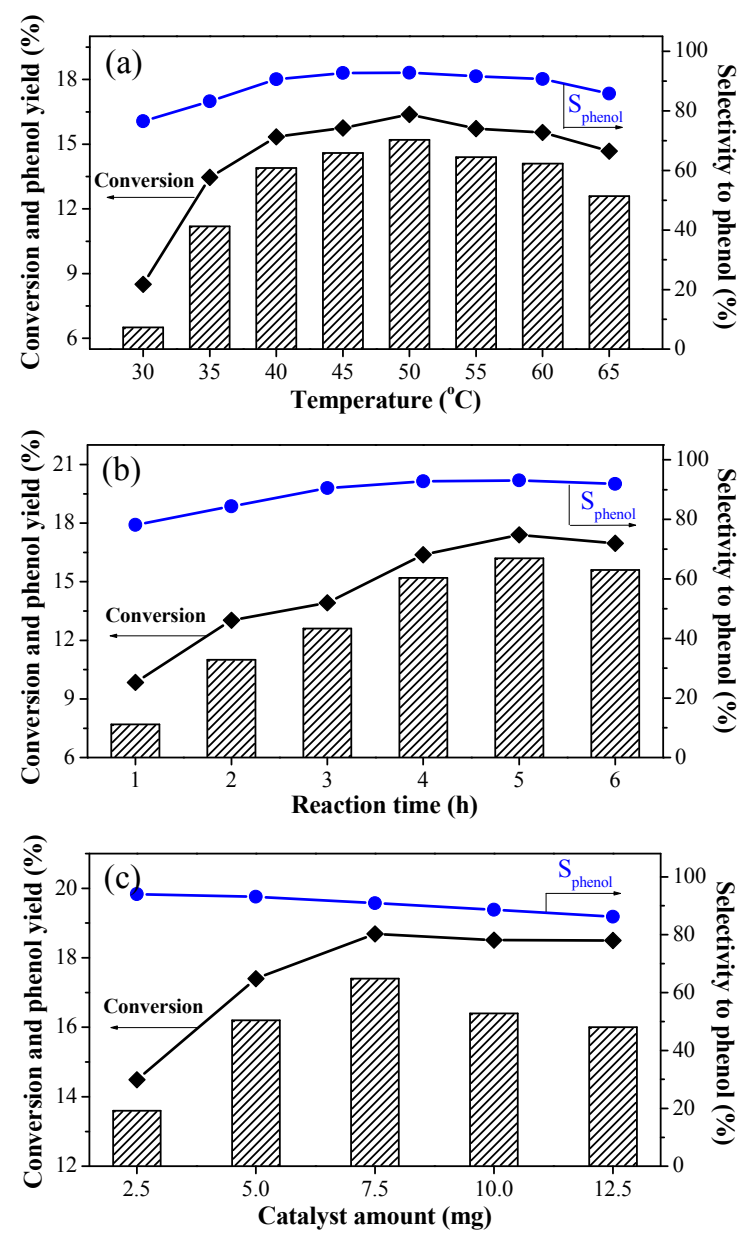

Figure 7. Effects of catalytic reaction temperature (a), reaction time (b), and catalyst amount (c) on catalytic activities over VG-N-A300 catalyst (benzene conversion ( $\bullet$ ) yield (column) and selectivity $(\bullet)$ of phenol). Reaction conditions: $0.3 \mathrm{~mL}$ of benzene, $5.0 \mathrm{~mL}$ of acetic acid, and $1.5 \mathrm{~mL}$ of $30 \%$ aq. $\mathrm{H}_{2} \mathrm{O}_{2}$; (a) $5.0 \mathrm{mg}$ of catalyst and $t=4 \mathrm{~h}$; (b) $5.0 \mathrm{mg}$ of catalyst and $\mathrm{T}=50^{\circ} \mathrm{C}$; and (c) $\mathrm{T}=50^{\circ} \mathrm{C}$ and $t=5 \mathrm{~h}$.

\section{Experimental Section}

\subsection{Materials}

Hydrogen peroxide $\left(\mathrm{H}_{2} \mathrm{O}_{2}, 30 \%\right)$, ethanol (AR), graphite powder (SP), sulfuric acid $\left(\mathrm{H}_{2} \mathrm{SO}_{4}\right.$, $98 \%)$, hydrochloric acid $(\mathrm{HCl}, 37 \%)$ and ammonium vanadate $\left(\mathrm{NH}_{4} \mathrm{VO}_{3}, \mathrm{AR}\right)$ were purchased from Sinopharm Chemical Reagent Co. Ltd., Shanghai, China. Benzene (AR), toluene (AR), aceticacid (AR), potassium permanganate $\left(\mathrm{KMnO}_{4}, \mathrm{AR}\right)$ were purchased from Kemiou Chemical Reagent Co. Ltd., 
Tianjin, China. Cetyltrimethyl-ammonium bromide (CTAB, 99.0\%) were purchased from Aladdin, Shanghai, China. All chemicals were used as received without any further purification.

\subsection{Synthesis of Graphite Oxide}

Graphite oxide (GO) was prepared by oxidation of graphite according to the Hummers method [48]. Briefly, graphite powder $(2 \mathrm{~g})$ was firstly added in concentrated sulfuric acid $(50 \mathrm{~mL})$ at $0{ }^{\circ} \mathrm{C}$, then potassium permanganate $(6 \mathrm{~g})$ was added gradually into the solution with vigorous stirring. Afterwards, the stirring was continued for $1.5 \mathrm{~h}$ at $0{ }^{\circ} \mathrm{C}$ and $2 \mathrm{~h}$ at $35^{\circ} \mathrm{C}$. Followed by the addition of deionized water $(100 \mathrm{~mL})$, the reaction solution was heated up to $98^{\circ} \mathrm{C}$ and maintained for $15 \mathrm{~min}$. Subsequently, a large amount of deionized water $(250 \mathrm{~mL})$ and $30 \%$ aqueous $\mathrm{H}_{2} \mathrm{O}_{2}(10 \mathrm{~mL})$ were poured into the reaction system to terminate the reaction. Finally, the resultant suspension was filtered and washed with $10 \% \mathrm{HCl}(500 \mathrm{~mL})$ and deionized water. The obtained product was fully dried at $40{ }^{\circ} \mathrm{C}$ for $24 \mathrm{~h}$.

\subsection{Synthesis of $V O_{x} / R G O$}

For the synthesis of $\mathrm{VO}_{x} / \mathrm{RGO}$ composites, the GO precursor $(50 \mathrm{mg}$ ) was firstly dispersed in ethanol $(35 \mathrm{~mL})$ with the assist of ultrasonic $(400 \mathrm{~W})$ for $45 \mathrm{~min}$. The cetyltrimethylammonium bromide (CTAB, $100 \mathrm{mg}$ ) was added into the $\mathrm{GO}$ suspension and an ultrasonic treatment for $15 \mathrm{~min}$ was performed. After stirring for $2 \mathrm{~h}$, the $\mathrm{NH}_{4} \mathrm{VO}_{3}$ aqueous solution $\left(0.02 \mathrm{~mol} \cdot \mathrm{L}^{-1}, 5 \mathrm{~mL}\right)$ was added dropwise into the resulting suspension in a further ultrasonic process (15 $\mathrm{min})$. The resulting suspension was stirred for $2 \mathrm{~h}$. Then, the suspension was transferred into a 50-mL Teflon-sealed autoclave and maintained at $160{ }^{\circ} \mathrm{C}$ for $24 \mathrm{~h}$. The resulting solid was filtered and washed with ethanol several times, followed by drying in vacuum at $60^{\circ} \mathrm{C}$ for $12 \mathrm{~h}$. Finally, the calcination treatments of as-synthesized $\mathrm{VO}_{x} / \mathrm{RGO}$ composites (VG-as) at different conditions gave rise to the final composite catalysts. The sample obtained by the direct calcination in air at $300^{\circ} \mathrm{C}$ for $2 \mathrm{~h}\left(2{ }^{\circ} \mathrm{C} \cdot \mathrm{min}^{-1}\right)$ was denoted as VG-A300. The samples achieved by the calcinations firstly in $\mathrm{N}_{2}\left(400{ }^{\circ} \mathrm{C}\right.$ for $4 \mathrm{~h}$ ) and subsequently in air $\left(300,350\right.$, and $\left.400^{\circ} \mathrm{C}\right)$ for $2 \mathrm{~h}$ with a heating rate of $2^{\circ} \mathrm{C} \cdot \mathrm{min}^{-1}$ were denoted as VG-N-A300, VG-N-A350, and VG-N-A400, respectively. The RGO reference sample was prepared by the solvothermal treatment of $\mathrm{GO}$ at $160^{\circ} \mathrm{C}$ for $24 \mathrm{~h}$ in ethanol, followed by the calcination in $\mathrm{N}_{2}$ at $400{ }^{\circ} \mathrm{C}$ for $4 \mathrm{~h}$.

\subsection{Characterization}

X-ray diffraction (XRD) measurements were performed on a D8 Advance X-ray diffractometer (Bruker, Karlsruhe, German) with $\mathrm{Cu} \mathrm{K} \alpha(\lambda=1.5418 \AA)$ radiation $(40 \mathrm{kV}, 40 \mathrm{~mA})$. Scanning electron microscope (SEM) micrographs were obtained on an S-4800 instrument (Hitachi, Tokyo, Japan) operating at $5.0 \mathrm{kV}$. Transmission electron microscopy (TEM) was taken on a JEM-2100 electron microscope (JEOL, Tokyo, Japan) with an acceleration voltage of $200 \mathrm{kV}$. Carbon-coated copper grids were used as sample holders for TEM analysis. The vanadium content of the samples was measured by using an X-ray fluorescence spectrometer (XRF) on a S4 Explorer instrument (Bruker, Karlsruhe, German). Fourier translation infrared spectroscopy (FT-IR) was acquired by using a Spectrum One FT-IR Spectrometer in KBr disks (PerkinElmer, Waltham, MA, USA). Raman spectra were recorded on a HR 800 spectrometer (HORIBA Jobin Yvon, Paris, France) with an $\mathrm{Ar}^{+}$ion laser $(457.9 \mathrm{~nm})$. The ultraviolet-visible diffuse reflectance spectra (UV-Vis DRS) of the samples were carried out using a Cary 5000 spectrophotometer (Varian, Palo Alto, CA, USA) equipped with a diffuse reflectance accessory. $\mathrm{BaSO}_{4}$ was used as a reference material. X-ray photoelectron spectroscopy (XPS) was detected on a Thermo ESCALAB 250 spectrometer (Thermo Fisher Scientific, Waltham, MA, USA), using a monochromatic $\mathrm{Al} \mathrm{K} \alpha \mathrm{X}$-ray source $(15 \mathrm{kV}, 150 \mathrm{~W})$ and analyzer pass energy of $100 \mathrm{eV}$. Binding energies (BEs) are referred to the $C(1 \mathrm{~s})$ binding energy of carbon taken to be $284.6 \mathrm{eV}$. The static water contact angle measurements were carried out on a XG-CAMA ${ }^{+}$contact angle meter (Xuanyichuangxi, Shanghai, China). Temperature-programmed reduction of hydrogen $\left(\mathrm{H}_{2}-\mathrm{TPR}\right)$ was performed using a full automatic instrument TP-5080 with a TCD detector (Xianquan, Tianjin, China). 
Typically, the sample $(10 \mathrm{mg})$ was packed into the reactor and degassed at $250{ }^{\circ} \mathrm{C}$ for $1 \mathrm{~h}$ with a nitrogen gas flow, then the sample was cooled down to the room temperature, and the gas flow was shifted to a mixture of $5 \mathrm{vol}$. \% $\mathrm{H}_{2}$ in $\mathrm{N}_{2}\left(20 \mathrm{~mL} \cdot \mathrm{min}^{-1}\right)$, the reactor was carried out by raising the temperature up to $800{ }^{\circ} \mathrm{C}$ at a heating rate of $10^{\circ} \mathrm{C} \cdot \mathrm{min}^{-1}$.

\subsection{Catalytic Evaluation}

The direct hydroxylation of benzene to phenol in liquid was performed in a 30-mL double layer glass reactor equipped with a reflux condenser, a superthermostat, and a magnetic stirrer. In a typical catalytic reaction process, $5.0 \mathrm{mg}$ of catalyst, $\mathrm{CH}_{3} \mathrm{COOH}(5 \mathrm{~mL})$, and benzene $(0.3 \mathrm{~mL}, 3.36 \mathrm{mmol})$ were added. The resultant mixture was heated to $30-65^{\circ} \mathrm{C}$, then $30 \%$ aqueous $\mathrm{H}_{2} \mathrm{O}_{2}(1.5 \mathrm{~mL}, 14.7 \mathrm{mmol})$ was added. The reaction process was allowed to continue for 1-6 h. Then, the liquid phase products were collected, filtered, and analyzed by a SP-3420 gas chromatograph (Beifen Ruili, Beijing, China) using a FID detector with an OV-1 capillary column $(30 \mathrm{~m} \times 0.25 \mathrm{~mm} \times 0.33 \mu \mathrm{m})$ (Zhongkekaidi, Lanzhou, China). The products of phenol, catechol, hydroquinone, and benzoquinone in liquid phase were further identified by GC-MS (Agilent 6890/5973N, Palo Alto, CA, USA). The quantitative calculation was achieved by the calibration curves using toluene as the standard after the catalytic reaction [23]. The conversion of benzene, yield of phenol, selectivity to phenol, and turnover number (TON) were calculated according to the reference [21].

Conversion of benzene $=($ Mole amount of phenol + benzoquinone + hydroquinone + catechol $) \times$ (Initial mole amount of benzene) ${ }^{-1} \times 100$.

Yield of phenol $(\%)=$ Mole amount of phenol $\times(\text { Initial mole amount of benzene })^{-1} \times 100$.

Selectivity to phenol $(\%)=$ Mole amount of phenol $\times($ Mole amount of phenol + benzoquinone + hydroquinone + catechol $)^{-1} \times 100$.

Turnover number $(\mathrm{TON})=$ Mole amount of phenol $\times(\text { Mole amount of vanadium sites })^{-1}$.

\section{Conclusions}

We have reported herein the synthesis, structure, and catalytic properties of $\mathrm{VO}_{x} / \mathrm{RGO}$ composite catalysts. The characterization results of XRD, SEM, TEM, FT-IR, Raman, XPS, XRF, H2-TPR, UV-Vis DRS, and contact angle analysis essentially confirmed the good fabrication of $\mathrm{VO}_{x} / \mathrm{RGO}$ composites by a simple solvothermal strategy. The $\mathrm{VO}_{x}$ nanoparticles were highly dispersed on the RGO sheets with a particle size of about $25 \mathrm{~nm}$. The surfactant CTAB played an important role for achieving the high dispersion of $\mathrm{VO}_{x}$ species. The resultant $\mathrm{VO}_{x} / \mathrm{RGO}$ composite catalysts were more efficient than the individual RGO and vanadium oxide catalysts in the direct hydroxylation of benzene to phenol. The enhanced catalytic performance may be contributed to not only the highly dispersed $\mathrm{VO}_{x}$ active species, but also the hydrophobic surface and huge $\pi$-electron system of RGO for the adsorption and activation of benzene. Furthermore, the calcinations were shown to have a significant influence on the structure and catalytic performance of $\mathrm{VO}_{x} / \mathrm{RGO}$ catalysts. The uniform $\mathrm{VO}_{x} \mathrm{NPs}$ with a high dispersion on the separated RGO sheets show a highly efficient catalytic performance, while the formation of a large amount of aggregated $\mathrm{H}_{x} \mathrm{~V}_{2} \mathrm{O}_{5}$ and bulk $\mathrm{V}_{2} \mathrm{O}_{5}$ species along with the destruction of RGO sheets are undesired for the hydroxylation of benzene. The well-structured VG-N-A300 gave the highest phenol yield at $17.4 \%$ under the optimized catalytic conditions.

Supplementary Materials: The following are available online at www.mdpi.com/2073-4344/6/5/74/s1, Figure S1: XRD patterns of the RGO reference sample, Figure S2: SEM (a) and TEM (b) images of the RGO reference sample, Figure S3: SEM (a) and TEM (b) images of as-synthesized $\mathrm{VO}_{x} /$ RGO composites (VG-as), Figure S4: TEM images of (a) $\mathrm{VO}_{x} / \mathrm{RGO}$ sample obtained in $\mathrm{H}_{2} \mathrm{O}$ solution and (b) $\mathrm{VO}_{x} / \mathrm{RGO}$ sample obtained without CTAB, Figure S5: XPS spectra of $\mathrm{C} 1 \mathrm{~s}$ region for GO and VG-N-A300, Figure S6: $\mathrm{H}_{2}$-TPR profile of $\mathrm{V}_{2} \mathrm{O}_{5}$, Figure S7: The static water contact angle pictures of (a) graphite, (b) RGO, (c) VG-N-A300, (d) VG-N-A350 and (e) VG-N-A400, Table S1: The atomic concentrations of $\mathrm{C}, \mathrm{O}, \mathrm{V}$, and $\mathrm{N}$, the peak area $(\mathrm{A})$ ratios of carbon-containing bonds to total carbon area $\left(\mathrm{A}_{\mathrm{T}}\right)$ and the distribution of surface $\mathrm{V}$ atoms according to XPS results. 
Acknowledgments: This work was supported by the National Natural Science Foundation of China (21203058), Natural Sciences Fund of Heilongjiang Province (B2015009, QC2016013), Postdoctoral Science-research Developmental Foundation of Heilongjiang Province of China (LBH-Q12022), Innovative Talents Program of Heilongjiang University of Science and Technology (Q20130202). We also thank the Project Sponsored by the Scientific Research Foundation for the Returned Overseas Chinese Scholars, State Education Ministry (2013-1792), Innovative Research Project of Key Laboratory of Functional Inorganic Material Chemistry (Heilongjiang University), Ministry of Education (2015).

Author Contributions: Y.Z. proposed, planned and designed the experiments. Y.D. and W.S. performed the experimental works. D.W., L.C. and F.Y. contributed to the data analysis. Y.D. and X.N. wrote the manuscript. Y.Z. supervised the project. All authors discussed the results and commended the manuscript.

Conflicts of Interest: The authors declare no conflict of interest.

\section{References}

1. Schmidt, R.J. Industrial catalytic processes-phenol production. Appl. Catal. A 2005, 280, 89-103. [CrossRef]

2. Balducci, L.; Bianchi, D.; Bortolo, R.; D'Aloisio, R.; Ricci, M.; Tassinari, R.; Ungarelli, R. Direct oxidation of benzene to phenol with hydrogen peroxide over a modified titanium silicalite. Angew. Chem. Int. Ed. 2003, 42, 4937-4940. [CrossRef] [PubMed]

3. Yuranov, I.; Bulushev, D.A.; Renken, A.; Kiwi-Minsker, L. Benzene to phenol hydroxylation with $\mathrm{N}_{2} \mathrm{O}$ over Fe- $\beta$ and Fe-ZSM-5: Comparison of activity per Fe-Site. Appl. Catal. A 2007, 319, 128-136. [CrossRef]

4. Li, Y.; Feng, Z.; van Santen, R.A.; Hensen, E.J.M.; Li, C. Surface functionalization of SBA-15-ordered mesoporous silicas: Oxidation of benzene to phenol by nitrous oxide. J. Catal. 2008, 255, 190-196. [CrossRef]

5. Borah, P.; Ma, X.; Nguyen, K.T.; Zhao, Y.L. A vanadyl complex grafted to periodic mesoporous organosilica: A green catalyst for selective hydroxylation of benzene to phenol. Angew. Chem. Int. Ed. 2012, 51, 7756-7761. [CrossRef] [PubMed]

6. Dong, Y.L.; Zhan, X.L.; Niu, X.Y.; Li, J.; Yuan, F.L.; Zhu, Y.J.; Fu, H.G. Facile Synthesis of Co-SBA-16 Mesoporous Molecular Sieves with EISA Method and Their Applications for Hydroxylation of Benzene. Microporous Mesoporous Mater. 2014, 185, 97-106. [CrossRef]

7. Bal, R.; Tada, M.; Sasaki, T.; Iwasawa, Y. Direct phenol synthesis by selective oxidation of benzene with molecular oxygen on an interstitial-N/Re cluster/zeolite catalyst. Angew. Chem. Int. Ed. 2006, 45, 448-452. [CrossRef] [PubMed]

8. Luo, G.H.; Lv, X.H.; Wang, X.W.; Yan, S.; Gao, X.H.; Xu, J.; Ma, H.; Jiao, Y.J.; Li, F.Y.; Chen, J.Z. Direct hydroxylation of benzene to phenol with molecular oxygen over vanadium oxide nanospheres and study of its mechanism. RSC Adv. 2015, 5, 94164-94170. [CrossRef]

9. Niwa, S.; Eswaramoorthy, M.; Nair, J.; Raj, A.; Itoh, N.; Shoji, H.; Namba, T.; Mizukami, F. A one-step conversion of benzene to phenol with a palladium membrane. Science 2002, 295, 105-107. [CrossRef] [PubMed]

10. Lee, B.; Naito, H.; Hibino, T. Electrochemical oxidation of benzene to phenol. Angew. Chem. Int. Ed. 2012, 51, 440-444. [CrossRef] [PubMed]

11. Zhong, Y.K.; Li, G.Y.; Zhu, L.F.; Yan, Y.; Wu, G.; Hu, C.W. Low temperature hydroxylation of benzene to phenol by hydrogen peroxide over Fe/activated carbon catalyst. J. Mol. Catal. A 2007, 272, 169-173. [CrossRef]

12. Ohkubo, K.; Kobayashi, T.; Fukuzumi, S. Direct oxygenation of benzene to phenol using quinolinium ions as homogeneous photocatalysts. Angew. Chem. Int. Ed. 2011, 50, 8652-8655. [CrossRef] [PubMed]

13. Shoji, O.; Kunimatsu, T.; Kawakami, N.; Watanabe, Y. Highly selective hydroxylation of benzene to phenol by wild-type cytochrome P450BM3 assisted by decoy molecules. Angew. Chem. Int. Ed. 2013, 52, 6606-6610. [CrossRef] [PubMed]

14. Elkasabi, Y.; Mullen, C.A.; Boateng, A.A. Aqueous extractive upgrading of bio-oils created by tail-gas reactive pyrolysis to produce pure hydrocarbons and phenols. ACS Sustain. Chem. Eng. 2015, 3, 2809-2816. [CrossRef]

15. Mukarakate, C.; McBrayer, J.D.; Evans, T.J.; Budhi, S.; Robichaud, D.J.; Iisa, K.; ten Dam, J.; Watson, M.J.; Baldwin, R.M.; Nimlos, M.R. Catalytic fast pyrolysis of biomass: The reactions of water and aromatic intermediates produces phenols. Green Chem. 2015, 17, 4217-4227. [CrossRef] 
16. Ding, G.D.; Wang, W.T.; Jiang, T.; Han, B.X.; Fan, H.L.; Yang, G.Y. Highly selective synthesis of phenol from benzene over a vanadium-doped graphitic carbon nitride catalyst. ChemCatChem 2013, 5, 192-200. [CrossRef]

17. Kharat, A.N.; Moosavikia, S.; Jahromi, B.T.; Badiei, A. Liquid phase hydroxylation of benzene to phenol over vanadium substituted keggin anion supported on amine functionalized SBA-15. J. Mol. Catal. A 2011, 348, 14-19. [CrossRef]

18. Xu, J.; Jiang, Q.; Shang, J.K.; Wang, Y.; Li, Y.X. A Schiff-base-type vanadyl complex grafted on mesoporous carbon nitride: A new efficient catalyst for hydroxylation of benzene to phenol. RSC Adv. 2015, 5, 92526-92533. [CrossRef]

19. Guo, C.; Du, W.D.; Chen, G.; Shi, L.; Sun, Q. Influence of temperature on hydroxylation of benzene to phenol using molecular oxygen catalyzed by $\mathrm{V} / \mathrm{SiO}_{2}$. Catal. Commun. 2013, 37, 19-22. [CrossRef]

20. Gao, X.H.; Xu, J. A new application of clay-supported vanadium oxide catalyst to selective hydroxylation of benzene to phenol. Appl. Clay Sci. 2006, 33, 1-6. [CrossRef]

21. Guo, B.; Zhu, L.F.; Hu, X.K.; Zhang, Q.; Tong, D.M.; Li, G.Y.; Hu, C.W. Nature of vanadium species on vanadium silicalite-1 zeolite and their stability in hydroxylation reaction of benzene to phenol. Catal. Sci. Technol. 2011, 1, 1060-1067. [CrossRef]

22. Shang, S.S.; Chen, B.; Wang, L.Y.; Dai, W.; Zhang, Y.; Gao, S. High-performance recyclable V-N-C catalysts for the direct hydroxylation of benzene to phenol using molecular oxygen. RSC Adv. 2015, 5, 31965-31971. [CrossRef]

23. Zhu, Y.J.; Dong, Y.L.; Zhao, L.N.; Yuan, F.L. Preparation and characterization of mesoporous $\mathrm{VO}_{x} / \mathrm{SBA}^{-16}$ and their application for the direct catalytic hydroxylation of benzene to phenol. J. Mol. Catal. A 2010, 315, 205-212. [CrossRef]

24. Hu, L.Y.; Yue, B.; Chen, X.Y.; He, H.Y. Direct hydroxylation of benzene to phenol on Cu-V bimetal modified HMS catalysts. Catal. Commun. 2014, 43, 179-183. [CrossRef]

25. Xu, J.Q.; Liu, H.H.; Yang, R.G.; Li, G.Y.; Hu, C.W. Hydroxylation of benzene by activated carbon catalyst. Chin. J. Catal. 2012, 33, 1622-1630. [CrossRef]

26. Song, S.Q.; Yang, H.X.; Rao, R.C.; Liu, H.D.; Zhang, A.M. Defects of multi-walled carbon nanotubes as active sites for benzene hydroxylation to phenol in the presence of $\mathrm{H}_{2} \mathrm{O}_{2}$. Catal. Commun. 2010, 11, $783-787$. [CrossRef]

27. Yang, J.H.; Sun, G.; Gao, Y.J.; Zhao, H.B.; Tang, P.; Tan, J.; Lu, A.H.; Ma, D. Direct catalytic oxidation of benzene to phenol over metal-free graphene-based catalyst. Energy Environ. Sci. 2013, 6, 793-798. [CrossRef]

28. Jin, M.M.; Yang, R.G.; Zhao, M.F.; Li, G.Y.; Hu, C.W. Application of Fe/activated carbon catalysts in the hydroxylation of phenol to dihydroxybenzenes. Ind. Eng. Chem. Res. 2014, 53, 2932-2939. [CrossRef]

29. Zhu, J.J.; Kailasam, K.; Fischer, A.; Thomas, A. Supported cobalt oxide nanoparticles as catalyst for aerobic oxidation of alcohols in liquid phase. ACS Catal. 2011, 1, 342-347. [CrossRef]

30. Zhang, L.; Liu, H.H.; Li, G.Y.; Hu, C.W. Continuous flow reactor for hydroxylation of benzene to phenol by hydrogen peroxide. Chin. J. Chem. Phys. 2012, 25, 585-591. [CrossRef]

31. Zhang, H.B.; Pan, X.L.; Han, X.W.; Liu, X.M.; Wang, X.F.; Shen, W.L.; Bao, X.H. Enhancing chemical reactions in a confined hydrophobic environment: An NMR study of benzene hydroxylation in carbon nanotubes. Chem. Sci. 2013, 4, 1075-1078. [CrossRef]

32. Wang, X.Y.; Zhang, X.F.; He, X.L.; Ma, A.; Le, L.J.; Lin, S. Facile electrodeposition of flower-like PMo $12-\mathrm{Pt} / \mathrm{rGO}$ composite with enhanced electrocatalytic activity towards methanol oxidation. Catalysts 2015, 5, 1275-1288. [CrossRef]

33. Wang, W.T.; Ding, G.D.; Jiang, T.; Zhang, P.; Wu, T.B.; Han, B.X. Facile one-pot synthesis of $\mathrm{V}_{x} \mathrm{O}_{y} @ \mathrm{C}$ catalysts using sucrose for the direct hydroxylation of benzene to phenol. Green Chem. 2013, 15, 1150-1154. [CrossRef]

34. Song, S.Q.; Jiang, S.J.; Rao, R.C.; Yang, H.X.; Zhang, A.M. Bicomponent $\mathrm{VO}_{2}$-Defects/MWCNT catalyst for hydroxylation of benzene to phenol: Promoter effect of defects on catalytic performance. Appl. Catal. A 2011, 401, 215-219. [CrossRef]

35. Wang, C.; Hu, L.Y.; Hu, Y.C.; Ren, Y.H.; Chen, X.Y.; Yue, B.; He, H.Y. Direct hydroxylation of benzene to phenol over metal oxide supported graphene oxide catalysts. Catal. Commun. 2015, 68, 1-5. [CrossRef]

36. Li, D.; Kaner, R.B. Graphene-based materials. Science 2008, 320, 1170-1171. [CrossRef] [PubMed]

37. Upadhyay, R.K.; Soinb, N.; Roy, S.S. Role of graphene/metal oxide composites as photocatalysts, adsorbents and disinfectants in water treatment: A review. RSC Adv. 2014, 4, 3823-3851. [CrossRef] 
38. Song, W.N.; He, C.Y.; Zhang, W.; Gao, Y.C.; Yang, Y.X.; Wu, Y.Q.; Chen, Z.M.; Li, X.C.; Dong, Y.L. Synthesis and nonlinear optical properties of reduced graphene oxide hybrid material covalently functionalized with zinc phthalocyanine. Carbon 2014, 77, 1020-1030. [CrossRef]

39. Chen, S.Q.; Wang, Y. Microwave-assisted synthesis of a $\mathrm{Co}_{3} \mathrm{O}_{4}$-graphene sheet-on-sheet nanocomposite as a superior anode material for Li-ion batteries. J. Mater. Chem. 2010, 20, 9735-9739. [CrossRef]

40. Yan, H.J.; Tian, C.G.; Sun, L.; Wang, B.; Wang, L.; Yin, J.; Wu, A.P.; Fu, H.G. Small-sized and highly dispersed $\mathrm{WN}$ from $\left[\mathrm{SiO}_{4}\left(\mathrm{~W}_{3} \mathrm{O}_{9}\right)_{4}\right]^{4-}$ clusters loading on GO-derived graphene as promising carriers for methanol electro-oxidation. Energy Environ. Sci. 2014, 7, 1939-1949. [CrossRef]

41. Wang, P.; Wang, J.; Wang, X.; Yu, H.G.; Yu, J.G.; Lei, M.; Wang, Y.G. One-step synthesis of easy-recycling $\mathrm{TiO}_{2}$-rGO nanocomposite photocatalysts with enhanced photocatalytic activity. Appl. Catal. B 2013, 132-133, 452-459. [CrossRef]

42. Hu, J.; Dong, Y.L.; Chen, X.J.; Zhang, H.J.; Zheng, J.M.; Wang, Q.; Chen, X.G. A highly efficient catalyst: In situ growth of $\mathrm{Au}$ nanoparticles on graphene oxide- $\mathrm{Fe}_{3} \mathrm{O}_{4}$ nanocomposite support. Chem. Eng. J. 2014, 236, 1-8. [CrossRef]

43. Grigorieva, A.V.; Badalyan, S.M.; Goodilin, E.A.; Rumyantseva, M.N.; Gaskov, A.M.; Birkner, A.; Tretyakov, Y.D. Synthesis, structure, and sensor properties of vanadium pentoxide nanorods. Eur. J. Inorg. 2010, 2010, 5247-5253. [CrossRef]

44. Stankovich, S.; Dikin, D.A.; Piner, R.D.; Kohlhaas, K.A.; Kleinhammes, A.; Jia, Y.; Wu, Y.; Nguyen, S.T.; Ruoff, R.S. Synthesis of graphene-based nanosheets via chemical reduction of exfoliated graphite oxide. Carbon 2007, 45, 1558-1565. [CrossRef]

45. Zhang, B.; Chen, Y.; Liu, G.; Xu, L.Q.; Chen, J.N.; Zhu, C.X.; Neoh, K.G.; Kang, E.T. Push-pull archetype of reduced graphene oxide functionalized with polyfluorene for nonvolatile rewritable memory. J. Polym. Sci. A 2012, 50, 378-387. [CrossRef]

46. Sun, Y.; Yang, S.B.; Lv, L.P.; Lieberwirth, I.; Zhang, L.C.; Ding, C.X.; Chen, C.H. A composite film of reduced graphene oxide modified vanadium oxide nanoribbons as a free standing cathode material for rechargeable lithium batteries. J. Power Source 2013, 241, 168-172. [CrossRef]

47. Zhao, L.N.; Dong, Y.L.; Zhan, X.L.; Cheng, Y.; Zhu, Y.J.; Yuan, F.L.; Fu, H.G. One-pot hydrothermal synthesis of mesoporous V-SBA-16 with a function of the $\mathrm{pH}$ of the initial gel and its improved catalytic performance for benzene hydroxylation. Catal. Lett. 2012, 142, 619-626. [CrossRef]

48. Hummers, W.S.; Offeman, R.E. Preparation of graphitic oxide. J. Am. Chem. Soc. 1958, 80, 1339. [CrossRef] 